\title{
Pertumbuhan vegetatif hasil split Dendrobium (Dendrobium sp.) pada dua jenis pupuk nitrogen dan tempat tanam
}

\author{
(Vegetative growth results of split Dendrobium (Dendrobium sp.) on two types of nitrogen \\ fertilizer and place of planting)
}

\author{
I. S. Pratiwi, E. D. Purbajanti, dan E. Fuskhah \\ Agroecotechnology, Faculty of Animal and Agricultural Sciences, Diponegoro University \\ Tembalang Campus, Semarang 50275 - Indonesia \\ Corresponding E-mail:indah1592@gmail.com
}

\begin{abstract}
Orchids are ornamental plants that lived in the wild as epiphytes, utilized the visual side of the flower. Problems arise is a relatively long time to be able to enjoy the flowers. Split technique is an alternative that produces special orchids especially of Dendrobium type with the same properties as its mother in a relatively short time. The research was conducted in July-September 2017 in screen house, Faculty of Animal and Agricultural Sciences, Diponegoro University. This study aimed to know the interaction between type of nitrogen fertilizer and place of planting to vegetative growth of split Dendrobium sp. This study used Split Plot Design of Complete Randomized Design scheme with ten replications. The main plot was place of planting : $\mathrm{T} 1=$ attached to the coconut fiber then hung and $\mathrm{T} 2=$ grown in pot (coconut fiber) and subplot was the type of fertilizer : P1 = POC goat + Azolla microphylla, and $\mathrm{P} 2$ = Synthetic fertilizer. The variables observed were plant height, number of leaves, stem diameter, number of roots, and number of buds per plant. Data were analyzed by analysis of variance followed by LSD test at 5\% level. The results showed that hook planting places significantly increased plant height and stem diameter. Synthetic fertilizer significantly increased plant height and number of leaves. There was interaction between nitrogen fertilizer and place of planting to stem diameter on vegetative growth results of split Dendrobium (Dendrobium sp.).
\end{abstract}

Keywords : Dendrobium sp., nitrogen fertilizer, place of planting

\begin{abstract}
ABSTRAK
Anggrek merupakan tanaman hias yang hidup di alam bebas secara epifit, dimanfaatkan sisi visualnya terutama dari bentuk dan warna bunga. Masalah yang timbul adalah waktunya yang relatif lama untuk berbunga. Teknik split merupakan alternatif yang menghasilkan anggrek khususnya jenis Dendrobium dengan sifat sama seperti induknya dalam waktu yang relatif singkat. Penelitian dilaksanakan pada Juli-September 2017 di screen house, Departemen Pertanian, Fakultas Peternakan dan Pertanian, Universitas Diponegoro. Tujuan penelitian adalah untuk mengetahui pengaruh interaksi jenis pupuk dan tempat tanam terhadap pertumbuhan vegetatif hasil split Dendrobium sp. Penelitian ini menggunakan Rancangan Petak Terbagi (Split Plot) skema RAL dengan 10 kali ulangan. Petak utama (main plot) adalah tempat tanam: $\mathrm{T} 1=$ dilekatkan pada serabut kelapa kemudian digantung dan $\mathrm{T} 2=$ ditanam dalam pot (serabut kelapa) dan anak petak (sub plot) adalah jenis pupuk: P1 = POC kotoran kambing + Azolla microphylla, dan $\mathrm{P} 2=$ pupuk sintetis. Variabel yang diamati antara lain adalah tinggi tanaman, jumlah daun, diameter batang, jumlah akar, dan jumlah tunas per tanaman. Data yang diperoleh dianalisis dengan ANOVA dan dilanjutkan dengan uji BNT (Beda Nyata Terkecil) pada taraf 5\%. Hasil penelitian menunjukkan bahwa tempat tanam gantungan meningkatkan tinggi tanaman dan diameter batang secara signifikan. Pupuk sintetis meningkatkan tinggi tanaman dan jumlah daun secara signifikan. Terjadi interaksi antara pemberian pupuk nitrogen dan tempat tanam terhadap diameter batang pada pertumbuhan vegetatif hasil split Dendrobium (Dendrobium sp.).
\end{abstract}


Kata kunci : Dendrobium sp., pupuk nitrogen, tempat tanam

\section{PENDAHULUAN}

Tanaman anggrek merupakan tanaman yang cukup populer di seluruh penjuru dunia, hidup di alam bebas secara epifit dengan menumpang pada tumbuhan lain untuk merekatkan akarnya. Anggrek memiliki 800 genera dan 25.000 spesies di dunia serta tidak kurang dari 5000 spesies hidup di wilayah belantara Indonesia (Fauziah dkk., 2014). Anggrek banyak dimanfaatkan oleh masyarakat dari sisi visual bahkan sebagai koleksi, terutama dari bentuk dan warna bunganya, dapat pula dijadikan sebagai bunga potong yang memerlukan penanganan ekstra hatihati agar tidak mudah rusak. Potensi anggrek sebagai tanaman hias sangat mendorong usaha konservasi terutama oleh para pencinta anggrek untuk melakukan budidaya (Solihah, 2015).

Produksi anggrek di Indoesia semakin meningkat dari tahun ke tahun. Hasil produksi anggrek nasional diproyeksikan akan meningkat dengan rata-rata pertumbuhan 3.71 persen, sementara sasaran Rencana Kerja Strategis (Renstra) Kementerian Pertanian tahun 2015 2019 pertumbuhan rata-rata mencapai 4.64 persen. Proyeksi produksi tahun 2015 - 2019 telah mendekati angka 91 persen hingga 94 persen bila dibandingkan dengan angka sasaran renstra tahun 2015 - 2019 (Kementan, 2016).

Dendrobium memiliki daya tarik pada bunganya dengan berbagai ukuran, bentuk, dan warna, karena itu kerap kali dijadikan sebagai hiasan. Bunga Dendrobium juga dapat mekar dalam waktu yang lama walaupun sudah dijadikan sebagai bunga potong (Purwanto, 2016). Dendrobium termasuk marga yang disukai oleh konsumen selain karena perawatannya mudah juga tidak membutuhkan biaya yang mahal, bahkan di Pulau Jawa sudah banyak dibudidayakan.

Anggrek Dendrobium dapat diperbanyak secara generatif dan vegetatif. Perbanyakan generatif menggunakan biji, kelemahannya adalah membutuhkan waktu yang lama. Perbanyakan vegetatif yang relatif lebih cepat dapat dilakukan yaitu dengan pemisahan rumpun (split), menggunakan keiki, stek, ataupun kultur jaringan (Syammiah, 2006). Dendrobium diperbanyak dengan cara vegetatif salah satunya dengan split, yaitu memotong, memisahkan rumpun anggrek, dan biasanya dilakukan pada anggrek simpodial (Suratniasih dkk., 2017). Split yang biasa dilakukan untuk memperbanyak anggrek adalah pada tanaman yang masih segar atau ketika tanaman dalam kondisi sehat. Tanaman anggrek khususnya jenis Dendrobium juga dapat dibudidayakan dengan teknik split pada kondisi tanaman yang kurang baik, yaitu memotong bagian batang tanaman yang menguning dan hampir mati kemudian digantung hingga tumbuh tunas baru. Teknik split seperti ini menjadi inovasi baru dalam budidaya tanaman anggrek. Teknik ini cukup mudah dilakukan dan membuat tanaman anggrek menjadi memiliki nilai fungsi kembali karena menghasilkan tunas yang baru.

Anggrek pada umumnya tidak mampu menyediakan unsur-unsur yang dibutuhkan untuk hidupnya. Pemberian pupuk dilakukan untuk mengatasi masalah tersebut, yaitu memenuhi berbagai unsur hara yang dibutuhkan dalam pertumbuhan tanaman anggrek (Suradinata dkk., 2012). Pemberian pupuk dilakukan dengan penyemprotan melalui daun ataupun melalui media tanam, karena anggrek termasuk tanaman epifit yang utamanya menempel pada media tanam (Andalasari dkk., 2014).

Pupuk $\mathrm{N}$ yang biasa digunakan untuk tanaman anggrek adalah pupuk daun Growmore, namun pupuk ini merupakan pupuk kimia yang tidak ramah lingkungan. Alternatif pengganti pupuk daun Growmore dapat digunakan pupuk organik yang lebih ramah lingkungan. Pupuk organik terbuat dari bahan organik atau makhluk hidup yang mengalami pembusukan oleh mikroorganisme, dapat berbentuk padat maupun cair (Hadisuwito, 2007). Azolla adalah salah satu tumbuhan yang dapat dibuat menjadi pupuk daun, atau sebagai bahan baku campuran dalam pembuatan pupuk organik. Azolla mampu menambat unsur nitrogen dan melepaskan sisa nitrogen untuk tanaman (Simanjuntak, 2005). Kotoran hewan juga dapat dibuat menjadi pupuk organik dikarenakan juga mengandung unsur hara khususnya $\mathrm{N}$ yang dibutuhkan oleh tanaman (Hartatik dan Widowati, 2006). Berdasarkan hal 
tersebut, maka dilakukan penelitian penggunaan pupuk organik cair (POC) dari kotoran kambing dan Azolla microphylla untuk tanaman anggrek, khususnya Dendrobium yang dibandingkan dengan pupuk daun Growmore.

Media tanam yang sesuai untuk tanaman anggrek adalah media yang dapat menyimpan unsur hara, sehingga ketika dibutuhkan langsung dapat diserap oleh tanaman. Media tanam juga sebaiknya yang tidak terlalu rapat agar memudahkan pertumbuhan akar tanaman (Tirta, 2006). Berdasarkan hal tersebut, maka dilakukan penelitian penggunaan jenis tempat tanam dengan media, yaitu serabut kelapa utuh atau potongan (cocochip). Serabut kelapa juga cukup mudah didapat dan murah harganya, sehingga berpotensi untuk digunakan sebagai alternatif media tanam anggrek.

\section{MATERI DAN METODE}

\section{Materi}

Penelitian telah dilaksanakan pada bulan Juli - September 2017 di screen house, Departemen Pertanian Fakultas Peternakan dan Pertanian Universitas Diponegoro Semarang.

Alat yang digunakan dalam penelitian adalah polypot berdiameter $\pm 10,5 \mathrm{~cm}$, pisau/cutter, hand sprayer sebagai wadah air, botol plastik ukuran $1500 \mathrm{ml}$ sebagai wadah larutan stok pupuk, drum besar dan drum kecil sebagai wadah pembuatan pupuk organik cair, karung plastik sebagai wadah kotoran kambing dan Azolla microphylla saat difermentasikan, timbangan, sarung tangan, masker, tali rafia, kawat sebagai penggantung dan rak Dendrobium sp., penggaris untuk mengukur tinggi tanaman, jangka sorong untuk mengukur diameter batang, label, dan alat tulis untuk mencatat hasil pengamatan.

Bahan yang digunakan dalam penelitian adalah air, tetes tebu, EM4, yakult, kotoran kambing dan Azolla microphylla untuk pembuatan pupuk organik cair, pupuk sintetis yaitu pupuk daun Growmore, serabut kelapa sebagai media tanam anggrek, alkohol $70 \%$ untuk sterilisasi, insektisida (Minoltan $30 \mathrm{WP}$ ) untuk pengendalian serangga, dan fungisida (Dithane M-45) sebagai anti jamur. Bahan yang digunakan adalah bibit Dendrobium $s p$. hasil split yang berusia \pm 2 bulan.

\section{Prosedur Penelitian}

Setiap unit percobaan ditanam masingmasing satu tanaman. Anggrek yang dilekatkan pada serabut kelapa kemudian digantung pada gantungan kawat di langit-langit screen house dan polypot disusun di atas rak pada screen house. Bibit anggrek yang telah ditanam dibiarkan selama kurang lebih satu minggu dengan penyiraman air setiap pagi dan sore hari. Penyemprotan pupuk dilakukan mulai minggu kedua bulan ke-1 sampai bulan ke-3 penelitian, setiap 3 hari sekali, dan sesuai dosis masingmasing jenis pupuk yaitu $200 \mathrm{ml} / 1$ POC kotoran kambing+Azolla microphylla dan $2 \mathrm{~g} / \mathrm{l}$ pupuk daun Growmore. Pemeliharaan tanaman dengan disiram air setiap hari, disemprot dengan fungisida sekali dalam 1 minggu, dan pemberian insektisida sebagai pencegahan setiap 2 minggu sekali.

Parameter yang diamati adalah pertambahan tinggi tanaman diukur dari pangkal batang sampai titik tumbuh tanaman (titik mulai keluarnya daun yang baru) pada setiap minggu, pertambahan jumlah daun yang terbentuk (selain 2 daun pertama) pada setiap minggu, pertambahan diameter batang diukur pada bagian tengah batang (yang membentuk bulb) pada awal dan akhir pengamatan, pertambahan jumlah akar yang terbentuk (ujung akar yang berwarna hijau) pada awal dan akhir pengamatan, pertambahan jumlah tunas per tanaman yang terbentuk (selain tunas utama) pada akhir pengamatan. Pengamatan dilakukan selama dua belas minggu (tiga bulan).

\section{Rancangan Percobaan dan Analisis Data}

Penelitian dilakukan menggunakan Rancangan Petak Terbagi (Split Plot) skema RAL dengan 10 (sepuluh) kali ulangan. Petak utama (main plot) adalah tempat tanam : T1 = dilekatkan pada serabut kelapa kemudian digantung dan $\mathrm{T} 2=$ ditanam dalam polypot dengan media tanam potongan serabut kelapa (cocochip) dan anak petak (sub plot) adalah pupuk organik : P1 $=$ POC, dan $\mathrm{P} 2=$ pupuk sintetis. Analisis data menggunakan Analisis Ragam dan jika ada perbedaan akan diuji lanjut dengan uji BNT (Beda Nyata Terkecil) pada taraf $\alpha=5 \%$. Data yang tidak homogen ditransformasi ke dalam bentuk akar kuadrat atau log sebelum dianalisis ragam. 


\section{HASIL DAN PEMBAHASAN}

\section{Pertambahan Tinggi Tanaman}

Hasil analisis ragam menunjukkan bahwa jenis tempat tanam dan pupuk nitrogen memberikan pengaruh yang nyata terhadap pertambahan tinggi tanaman. Interaksi antara tempat tanam dengan pupuk nitrogren tidak memberikan pengaruh yang nyata terhadap pertambahan tinggi tanaman anggrek Dendrobium selama 12 minggu. Pertambahan tinggi tanaman anggrek Dendrobium setelah 12 minggu tersaji pada Tabel 1. pupuk daun Growmore lebih tinggi yaitu sebesar $32 \%$ dibandingkan dengan pupuk daun Bayfolan sebesar $11 \%$.

Hasil uji BNT menunjukkan bahwa perlakuan tempat tanam juga memberikan pengaruh nyata terhadap rerata pertambahan tinggi tanaman. Anggrek yang ditanam pada tempat tanam gantungan menghasilkan rerata pertambahan tinggi tanaman $1,51 \mathrm{~cm}$ adalah secara signifikan lebih tinggi dibandingkan anggrek yang ditanam pada tempat tanam polypot. Hal ini karena cahaya yang diserap tanaman anggrek yang ditanam pada tempat tanam polypot

Tabel 1. Pertambahan Tinggi Tanaman Anggrek Dendrobium pada Dua Jenis Pupuk Nitrogen dan Tempat Tanam Selama 12 Minggu

\begin{tabular}{|c|c|c|c|}
\hline \multirow{2}{*}{ Tempat Tanam } & \multicolumn{2}{|c|}{ Pupuk Nitrogen } & \multirow{2}{*}{ Rerata } \\
\hline & POC & Sintetis & \\
\hline & \multicolumn{3}{|c|}{ 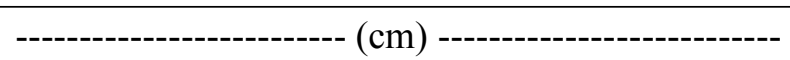 } \\
\hline Gantungan & 1,26 & 1,76 & $1,51^{\mathrm{b}}$ \\
\hline Polypot & 1,10 & 1,40 & $1,25^{\mathrm{a}}$ \\
\hline Rerata & $1,18^{\mathrm{a}}$ & $1,58^{\mathrm{b}}$ & \\
\hline
\end{tabular}

Superskrip berbeda pada baris dan kolom rerata menunjukkan perbedaan nyata pada uji BNT dengan $\alpha=5 \%$.

Berdasarkan Tabel 1 diketahui bahwa rerata pertambahan tinggi tanaman berbeda nyata pada perlakuan pemberian pupuk nitrogen. Pemberian pupuk sintetis menghasilkan rerata pertambahan tinggi tanaman sebesar $1,58 \mathrm{~cm}$ adalah lebih tinggi dibandingkan dengan perlakuan pemberian POC. Hasil ini karena pupuk sintetis merupakan pupuk kimia yang cepat terurai unsur haranya sehingga mudah diserap tanaman, sedangkan POC lambat menyediakan unsur hara yang dibutuhkan oleh tanaman. Hal ini didukung oleh Handayanto dkk. (2017) yang menyatakan bahwa pupuk organik proses penguraiannya lambat, sehingga nutrisi yang dikandungnya tidak langsung dapat diserap oleh tanaman. Penelitian Maera dkk. (2014) yang menggunakan plantlet anggrek Phalaenopsis dengan pemberian pupuk daun Growmore menunjukkan bahwa pupuk daun Growmore menghasilkan respon lebih tinggi daripada pupuk daun Bayfolan, dikarenakan kandungan $\mathrm{N}$ pada lebih sedikit dikarenakan terhalang oleh dinding polypot dibandingkan dengan anggrek yang ditanam pada tempat tanam gantungan. Hal ini didukung oleh Yasmin dkk. (2017) yang menyatakan bahwa tinggi tanaman juga berkaitan dengan cahaya, tanaman yang mendapat cahaya matahari yang cukup, maka pertumbuhan tinggi tanaman semakin optimal. Suradinata dkk. (2012) menambahkan bahwa faktor yang mempengaruhi tinggi tanaman adalah ketersediaan cahaya yang cukup sehingga memacu pertumbuhan tanaman dengan pemanjangan sel.

\section{Pertambahan Jumlah Daun}

Hasil analisis ragam pertambahan jumlah daun menunjukkan bahwa jenis tempat tanam tidak memberikan pengaruh yang nyata terhadap pertambahan jumlah daun. Jenis pupuk nitrogen memberikan pengaruh yang nyata pada pertambahan jumlah daun anggrek Dendrobium. 
Interaksi antara tempat tanam dengan jenis pupuk nitrogren tidak memberikan pengaruh yang nyata terhadap pertambahan jumlah daun tanaman anggrek Dendrobium pada umur 12 minggu. Pertambahan jumlah daun tanaman anggrek Dendrobium setelah 12 minggu tersaji pada Tabel 2. sel yang membelah hanya sedikit atau sel belum aktif membelah. Hal ini sesuai dengan Suradinata dkk. (2012) yang menyatakan bahwa tanaman yang telah dewasa memiliki daun yang lebih banyak daripada tanaman yang baru bertumbuh.

Hasil uji ANOVA menunjukkan bahwa tidak ada perbedaan yang nyata antara rerata

Tabel 2. Pertambahan Jumlah Daun Anggrek Dendrobium pada Dua Jenis Pupuk Nitrogen Tempat Tanam Selama 12 Minggu

\begin{tabular}{|c|c|c|c|}
\hline \multirow{2}{*}{ Tempat Tanam } & \multicolumn{2}{|c|}{ Pupuk Nitrogen } & \multirow{2}{*}{ Rerata } \\
\hline & POC & Sintetis & \\
\hline & \multicolumn{3}{|c|}{------------------------- (helai) -------------------------- } \\
\hline Gantungan & 0,80 & 1,60 & 1,20 \\
\hline Polypot & 0,60 & 1,40 & 1,00 \\
\hline Rerata & $0,70^{\mathrm{a}}$ & $1,50^{\mathrm{b}}$ & \\
\hline
\end{tabular}

$\overline{\text { Superskrip berbeda pada baris rerata menunjukkan perbedaan nyata pada uji BNT dengan } \alpha}=5 \%$.

Berdasarkan hasil uji BNT pada Tabel 2 diketahui bahwa pemberian POC menghasilkan rerata pertambahan jumlah daun lebih rendah dibandingkan dengan perlakuan pemberian pupuk sintetis. Rerata pertambahan jumlah daun anggrek pada pemberian pupuk sintetis adalah 1,50 helai dan pemberian POC hanya 0,70 helai. Hasil ini karena POC merupakan pupuk alami yang lama menguraikan unsur haranya yang tidak mudah bereaksi dengan media tanam sehingga unsur hara yang dibutuhkan tanaman menjadi lambat tersedia, sedangkan pupuk sintetis cepat menguraikan unsur haranya sehingga mudah diserap tanaman. Hal ini didukung oleh Handayanto dkk. (2017) yang menyatakan bahwa unsur hara pupuk anorganik mudah diserap tanaman karena proses penguraiannya cepat. Hasil penelitian Krishardianto dan Dewi (2017) menyatakan bahwa pupuk anorganik atau NPK 32:10:10 menunjukkan pengaruh yang paling tinggi terhadap pertambahan jumlah daun untuk anggrek Cattleya. Jumlah daun yang terbentuk secara keseluruhan belum terlalu banyak karena masih dalam fase awal pertumbuhan. Hasil tersebut karena pada masa awal pertumbuhan sel- pertambahan jumlah daun anggrek yang ditanam pada tempat tanam gantungan dengan polypot. Rerata Pertambahan jumlah daun yang dihasilkan anggrek yang ditanam pada tempat tanam gantungan sama dengan pertambahan jumlah daun anggrek yang ditanam pada tempat tanam polypot. Perbedaan tempat tanam gantungan dan polypot belum mempengaruhi pertambahan jumlah daun secara signifikan. Hal ini dikarenakan selain dipengaruhi ketersediaan unsur hara, pertambahan jumlah daun juga dipengaruhi faktor lingkungan. Tempat tanam anggrek termasuk faktor lingkungan yang berkaitan dengan faktor lingkungan yang lain. Tanaman anggrek yang ditanam menggunakan pot atau digantung dengan seutas kawat, berkaitan dengan kondisi cahaya dan air yang ada pada tempat tanam. Kondisi tanaman terlalu kering akibat cahaya yang berlebihan, yang juga menyebabkan air pada tempat tanam menjadi cepat menguap. Sarwono (2002) menyatakan bahwa tempat tanam adalah tempat peletakan media tanam yang berpengaruh terhadap pertumbuhan tanaman. Tanaman yang kekurangan atau kelebihan air akan kehilangan daya serapnya terhadap unsur hara. Suradinata 
dkk. (2012) menambahkan bahwa cahaya adalah faktor lingkungan yang berperan dalam mensuplai energi bagi tanaman untuk melakukan fotosintesis.

\section{Pertambahan Diameter Batang}

Hasil analisis ragam diameter batang menunjukkan bahwa jenis pupuk nitrogen tidak memberikan pengaruh yang nyata terhadap pertambahan diameter batang. Jenis tempat tanam dan interaksi antara tempat tanam dengan pupuk nitrogren memberikan pengaruh yang nyata terhadap pertambahan diameter batang tanaman anggrek Dendrobium pada umur 12 minggu. Pertambahan diameter batang tanaman anggrek Dendrobium setelah 12 minggu tersaji pada Tabel 3. juga terjaga kelembabannya, sehingga mengakibatkan penguapan yang terjadi lebih kecil dibandingkan pada tempat tanam gantungan. Nesiaty dan Maloedyn (2007) menambahkan bahwa anggrek yang ditanam menggunakan media tanam yang digantung harus lebih sering disiram dibandingkan dengan yang ditanam di dalam pot untuk menjaga kelembaban tanaman.

Berdasarkan penelitian diketahui bahwa pemberian pupuk sintetis memberikan hasil pertambahan diameter batang yang sama antara tempat tanam gantungan dan tempat tanam polypot. Penelitian Wardani dkk. (2009) yang menyatakan bahwa perlakuan jenis pupuk daun majemuk NPK seimbang dengan konsentrasi pupuk daun $2 \mathrm{~g} / \mathrm{l}$ menunjukkan diameter

Tabel 3. Pertambahan Diameter Batang Anggrek Dendrobium sp. pada Dua Jenis Tempat Tanam dan Pupuk Nitrogen Selama 12 Minggu

\begin{tabular}{llcc}
\hline \hline \multirow{2}{*}{ Tempat Tanam } & \multicolumn{2}{c}{ Pupuk Nitrogen } & \multirow{2}{*}{ Rerata } \\
\cline { 2 - 3 } & POC & Sintetis & \\
\hline \multirow{3}{*}{ Gantungan } & ---------------- \\
Polypot & $0,11^{\mathrm{a}}$ & $0,12^{\mathrm{a}}$ & $0,11^{\mathrm{a}}$ \\
Rerata & $0,14^{\mathrm{b}}$ & $0,13^{\mathrm{a}}$ & $0,14^{\mathrm{b}}$ \\
\hline
\end{tabular}

Superskrip berbeda pada kolom rerata atau matrik interaksi menunjukkan perbedaan nyata pada uji BNT dengan $\alpha=5 \%$.

Berdasarkan Tabel 3 diketahui bahwa terdapat interaksi antara faktor tempat tanam dan pupuk nitrogen. Interaksi antara pemberian POC dengan tempat tanam menunjukkan hasil lebih tinggi pada tempat tanam polypot yaitu $0,14 \mathrm{~cm}$ dibanding pada tempat tanam gantungan. Hasil tersebut dikarenakan unsur hara yang dibutuhkan tanaman tersimpan lebih banyak pada tempat tanam polypot dibanding dengan tempat tanam gantungan, sehingga batang tanaman menjadi lebih besar pada tempat tanam polypot. Hal tersebut didukung oleh hasil penelitian Wardani dkk. (2009) bahwa tanaman biasanya menghasilkan diameter pseudobulb anakan yang semakin besar karena cadangan makanan tersimpan pada pseudobulb (batang semu). Anggrek yang ditanam pada tempat tanam polypot pseudobulb optimum, namun semakin tinggi konsentrasi pupuk akan menghasilkan diameter pseudobulb yang kecil. Hal ini didukung dengan hasil penelitian Burhan (2016) bahwa pupuk NPK dengan komposisi 20-15-15 dan 10-40-15 tidak berpengaruh terhadap diameter batang Dendrobium. Pupuk sintetis yang diberikan mengandung unsur hara yang tidak seimbang antara N, P, dan K yaitu dengan perbandingan 3210-10. Nesiaty dan Maloedyn (2007) menambahkan kebutuhan unsur hara untuk tanaman anggrek muda diberikan pupuk berimbang antara $\mathrm{N}, \mathrm{P}$, dan $\mathrm{K}$.

\section{Pertambahan Jumlah Akar}

Hasil analisis ragam jumlah akar menunjukkan bahwa jenis tempat tanam dan 
pupuk nitrogen serta interaksi antara tempat tanam dengan pupuk nitrogen belum memberikan pengaruh yang nyata terhadap pertambahan jumlah akar tanaman anggrek Dendrobium pada umur 12 minggu. Pertambahan jumlah akar tanaman anggrek Dendrobium pada dua jenis tempat tanam dan pupuk nitrogen setelah 12 minggu tersaji pada Tabel 4. kondisi cahaya dan air yang ada pada tempat tanam. Berdasarkan Tabel 4 diketahui bahwa pertambahan jumlah akar anggrek yang ditanam pada tempat tanam polypot sama dengan tempat tanam gantungan. Hal tersebut dikarenakan kondisi cahaya yang membuat suhu udara terlalu tinggi, sehingga unsur hara pada media tanam mudah hilang akibat penguapan berlebih. Air yang

Tabel 4. Pertambahan Jumlah Akar Anggrek Dendrobium pada Dua Jenis Tempat Tanam dan Pupuk Nitrogen Selama 12 Minggu

\begin{tabular}{llcc}
\hline \hline \multirow{2}{*}{ Tempat Tanam } & \multicolumn{2}{l}{ Pupuk Nitrogen } & \multirow{2}{*}{ Rerata } \\
\cline { 2 - 3 } & POC & Sintetis & \\
\hline \multirow{3}{*}{ Gantungan } & $---{ }^{\prime}$ & 3,00 & 2,40 \\
Polypot & 2,40 & 3,00 & 2,70 \\
Rerata & 2,10 & 3,00 & \\
\hline
\end{tabular}

Hasil uji BNT menunjukkan bahwa jenis tempat tanam dan pupuk nitrogen tidak menyebabkan perbedaan jumlah akar. Berdasarkan penelitian didapatkan hasil perlakuan pemberian POC menghasilkan pertambahan jumlah akar sama dengan perlakuan pupuk sintetis. Hasil pemberian pupuk sintetis adalah 2,10 buah dan pemberian POC adalah 3,00 buah. Hasil tersebut karena kandungan unsur hara yang dibutuhkan untuk pertumbuhan akar yaitu fosfor belum memenuhi kebutuhan tanaman. Kandungan unsur hara fosfor untuk pertumbuhan akar pada POC dan pupuk sintetis yaitu sebesar $10 \%$. Hal ini didukung oleh Nesiaty dan Maleodyn (2007) bahwa unsur hara fosfor berperan di dalam pembentukan sel dan merangsang pertumbuhan akar. Penelitian Hasanah dkk. (2014) yang menyatakan bahwa pemberian pupuk daun meningkatkan jumlah akar lebih banyak dengan kandungan fosfor yang tinggi.

Hasil uji ANOVA menunjukkan bahwa tidak ada perbedaan yang nyata antara pertambahan jumlah akar anggrek yang ditanam pada tempat tanam gantungan dengan polypot. Tanaman anggrek yang ditanam menggunakan pot atau digantung dengan seutas kawat, berkaitan dengan hilang menyebabkan unsur hara tidak terserap dengan baik oleh tanaman. Sarwono (2002) menyatakan bahwa tanaman yang kekurangan air akan kehilangan daya serapnya terhadap unsur hara. Kondisi cahaya yang berlebih tersebut juga membuat media tanam pada tempat tanam menjadi kering. Penelitian Widiastoety dan Marwoto (2004) yang menyatakan bahwa intensitas cahaya yang rendah dapat merangsang zat tumbuh endogen bekerja lebih aktif dalam melakukan proses pembentukan akar.

\section{Pertambahan Jumlah Tunas Per Tanaman}

Hasil analisis ragam jumlah tunas per tanaman menunjukkan bahwa jenis tempat tanam dan pupuk nitrogen serta interaksi antara tempat tanam dengan pupuk nitrogen belum memberikan pengaruh yang nyata terhadap pertambahan jumlah tunas per tanaman anggrek Dendrobium pada umur 12 minggu. Pertambahan jumlah tunas per tanaman anggrek Dendrobium pada dua jenis tempat tanam dan pupuk nitrogen setelah 12 minggu tersaji pada Tabel 5.

Hasil uji BNT menunjukkan bahwa jenis tempat tanam dan pupuk nitrogen tidak menyebabkan perbedaan jumlah tunas per 
Tabel 5. Pertambahan Jumlah Tunas Per Tanaman Anggrek Dendrrobium pada Dua Jenis Tempat Tanam dan Pupuk Nitrogen Selama 12 Minggu

\begin{tabular}{|c|c|c|c|}
\hline \multirow{2}{*}{ Tempat Tanam } & \multicolumn{2}{|c|}{ Pupuk Nitrogen } & \multirow{2}{*}{ Rerata } \\
\hline & POC & Sintetis & \\
\hline & \multicolumn{3}{|c|}{ 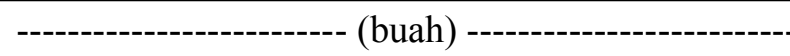 } \\
\hline Gantungan & 0,50 & 1,00 & 0,75 \\
\hline Polypot & 0,40 & 0,40 & 0,40 \\
\hline Rerata & 0,45 & 0,70 & \\
\hline
\end{tabular}

tanaman. Perlakuan pemberian pupuk sintetis dan POC tidak memberikan perbedaan nyata terhadap jumlah tunas per tanaman. Pertambahan jumlah tunas per tanaman pada pemberian pupuk sintetis adalah sama dengan pemberian POC. Tunas baru tumbuh dikarenakan komposisi hara pada pupuk lengkap dengan nitrogen yang tinggi sebesar 32 $\%$. Hal ini sesuai dengan Wardani dkk. (2009) yang menyatakan bahwa pupuk majemuk foliar mengandung unsur nitrogen yang tinggi sehingga dapat merangsang pemunculan tunas baru. Pertumbuhan anggrek Dendrobium belum optimal, sehingga tunas baru yang tumbuh maksimal hanya berjumlah 2 pada akhir pengamatan. Penelitian Krishardianto dan Dewi (2017) bahwa perlakuan pupuk anorganik dan organik tidak memberikan pengaruh nyata terhadap munculnya anakan baru pada anggrek Cattleya, akan tetapi anakan baru muncul pada minggu ke 8 untuk pupuk anorganik dan minggu ke 12 untuk pupuk organik dengan rata-rata 2 anakan.

Berdasarkan Tabel 5 diketahui bahwa pertambahan jumlah tunas per tanaman anggrek pada tempat tanam gantungan sama dengan tempat tanam polypot. Tempat tanam anggrek termasuk faktor lingkungan yang berkaitan dengan faktor lingkungan yang lain. Tanaman yang ditanam pada tempat tanam harus dijaga kelembaban media tanamnya. Hal ini didukung oleh Iswanto (2002) yang menyatakan bahwa anggrek membutuhkan kelembaban antara $60-80$ $\%$. Pencegahan terhadap kelembaban yang terlalu tinggi adalah menghindari terlalu basahnya media tanam, sedangkan pencegahan terhadap kelembaban yang terlalu rendah. Kondisi media tanam yang kering atau lembab menyebabkan pertumbuhan tunas menjadi tidak optimal, dikarenakan mempengaruhi ketersediaan unsur hara yang dibutuhkan oleh tanaman. Penelitian Tirta (2006) yang mengungkapkan bahwa unsur hara mempengaruhi pertumbuhan tanaman. Semakin banyak unsur hara yang diserap, maka semakin meningkatnya fotosintat sehingga meningkatkan pertumbuhan organ-organ vegetatif.

\section{KESIMPULAN}

Tempat tanam gantungan meningkatkan tinggi tanaman dan diameter batang, namun tidak menyebabkan perbedaan terhadap jumlah daun, jumlah akar dan jumlah tunas per tanaman. Pupuk sintetis meningkatkan tinggi tanaman dan jumlah daun secara signifikan, namun tidak menyebabkan perbedaan terhadap diameter batang, jumlah akar dan jumlah tunas per tanaman. Interaksi dua jenis pupuk nitrogen dan tempat tanam berpengaruh nyata terhadap diameter batang, namun belum berpengaruh nyata terhadap tinggi tanaman, jumlah daun, jumlah akar dan jumlah tunas per tanaman pada pertumbuhan vegetatif hasil split Dendrobium (Dendrobium sp.).

\section{DAFTAR PUSTAKA}

Andalasari, T. D., Yafisham, dan Nuraini. 2014. Respon pertumbuhan anggrek dendrobium terhadap jenis media tanam dan pupuk daun. J. Penelitian Pertanian Terapan 14 (3) : 167-173. 
Burhan, Badri. 2016. Pengaruh jenis pupuk dan konsentrasi benzyladenin (BA) terhadap pertumbuhan dan pembungaan anggrek dendrobium hibrida. J. Penelitian Pertanian Terapan 16 (3) : 194-204.

Fauziah, N., S. A. Aziz, dan D. Sukma. 2014. Karakterisasi morfologi anggrek Phalaenopsis spp. asli indonesia. Bul. Agrohorti 2 (1) : 86-94.

Hadisuwito, Sukamto. 2007. Membuat Pupuk Kompos Cair. AgroMedia Pustaka, Jakarta.

Handayanto, E., N. Muddarisna, dan A. Fiqri. 2017. Pengelolaan Kesuburan Tanah. UB Press, Malang.

Hartatik dan Widowati. 2007. Pupuk Organik dan Pupuk Hayati. Balai Besar Litbang Sumberdaya Lahan Pertanian, Bogor.

Hasanah, U., E. Suwarsi R., dan Sumadi. 2014. Pemanfataan pupuk daun, air kelapa dan bubur pisang sebagai komponen medium pertumbuhan plantlet anggrek dendrobium kelemense. J. Biosaintifika 6 (2) : 161-168.

Iswanto, H. 2002. Petunjuk Perawatan Anggrek. AgroMedia Pustaka, Jakarta.

Krishardianto, A. dan D. Sukma. 2017. Karakterisasi morfologi dan pengaruh perlakuan pemupukan dan pemberian silika (si) pada genotipe hibrida anggrek cattleya. Bul. Agrohorti 5 (2) : 167-175.

Kementerian Pertanian. 2016. Rencana Strategis Kementerian Pertanian 2015 - 2019. Kementerian Pertanian Republik Indonesia, Jakarta.

Maera, Z., Yusnita, dan Susriana. 2014. Respon pertumbuhan planlet anggrek phalaenopsis hibrida terhadap pemberian dua jenis pupuk daun dan benziladenin selama aklimatisasi. J. Enviagro 7 (2) : 33-38.

Nesiaty, S. dan M. Sitanggang. 2007. Kiat Sukses Membungakan Anggrek. AgroMedia
Pustaka, Jakarta.

Purwanto, A. W. 2016. Anggrek - Budidaya dan Perbanyakan. LPPM UPN Veteran Yogyakarta Press, Daerah Istimewa Yogyakarta.

Sabran, M., A. Krismawati, Y. R. Galingging, dan M. A. Firmansyah. 2003. Eksplorasi dan Karakterisasi Tanaman Anggrek di Kalimantan Tengah. Bul. Plasma Nutfah, 9 (1) : $1-6$.

Sarwono, B. 2002. Menghasilkan Anggrek Potong Kualitas Prima. AgroMedia Pustaka, Jakarta.

Simanjuntak, Linus. 2005. Usaha Tani Terpadu Pati Padi, Azolla, Tiktok, dan Ikan. AgroMedia Pustaka, Jakarta.

Solihah, S. M. 2015. Koleksi, status dan potensi anggrek di kebun raya liwa. Warta Kebun Raya, 13 (1) : 15-23.

Suradinata, Y. R., A. Nuraini, dan A. Setiadi. 2012. Pengaruh kombinasi media tanam dan konsentrasi pupuk daun terhadap pertumbuhan tanaman anggrek Dendrobium $s p$. pada tahap aklimatisasi. J. Agrivigor 11 (2) : 104-116.

Suratniasih, N. K. M., I. A. Astarini, dan I G. A S. Wahyuni. 2017. Panjang batang dan konsentrasi zat pengatur tumbuh zeatin berpengaruh terhadap pertumbuhan vegetatif anggrek Dendrobium sonia. J. Metamorfosa 4 (2) : 271-278.

Syammiah, S. 2006. Jenis senyawa organik suplemen pada medium knudson c untuk pertumbuhan protocorm like bodies dendrobium bertacong blue $\mathrm{x}$ dendrobium undulatum. J. Floratek. 2 : 86-92.

Tirta, I. G. 2006. Pengaruh beberapa jenis media tanam dan pupuk daun terhadap pertumbuhan vegetatif anggrek jamrud (Dendrobium macrophyllum A. Rich). Biodiversitas 7 (1) : 81-84. 
Wardani, S., H. Setiado, dan S. Ilyas. 2009. Pengaruh media tanam dan pupuk daun terhadap aklimatisasi anggrek dendrobium (Dendrobium sp.). J. Ilmu Pertanian Kultivar 5 (1) : 11-18.

Widiastoety, D. dan B. Sarwoto. 2004. Pengaruh Berbagai Sumber Arang dalam Me dia
Kultur In Vi tro terhadap Pertumbuhan Plantlet Oncidium. J. Hort., 14 (1) : 1-5.

Yasmin, Z. F., S. I. Aisyah, dan D. Sukma. 2017. Pembibitan (Kultur Jaringan hingga Pembesaran) Anggrek Phalaenopsis di Hasanudin Orchids, Jawa Timur. Bul. Agrohorti, 6 (3) : 411-420. 